\title{
Merkez Bölge (Kor) Kas Kuvvetinin Değerlendirilmesi için İzometrik Test Bataryasının Geliştirilmesi ve Geçerliliğinin Sağlanması
}

\author{
Necla ALTINOK ${ }^{1}$, Asuman ŞAHAN, ${ }^{1 *}$ K.Alparslan ERMAN ${ }^{1}$, Ahmet UZUN ${ }^{\mathbf{2}}$ \\ ${ }^{1}$ Akdeniz Üniversitesi, Spor Bilimleri Fakültesi \\ ${ }^{2}$ Necmettin Erbakan Üniversitesi, Beden Eğitimi ve Spor Bölümü
}

$\ddot{\mathbf{O} z}$

Orijinal Makale

Çalışmanın amacı kor kaslarında kuvvetinin değerlendirilmesi için tasarlanmış izometrik bir test bataryasının geliştirilmesi ve geçerliliğinin sağlanmasıdır. Araştırmaya yas

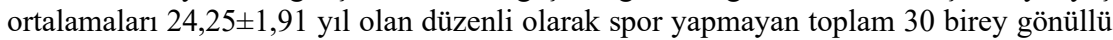
olarak katılmıştır. Çalışmada yer alan tüm katılımcılara kuvvet testlerinden önce $10 \mathrm{dk}$ 1sınma yaptırılmıştır. Merkez bölgesi için toplam 8 hareket test olarak uygulanmış ve 2 adet merkez kuvveti ölçen geçerliliği ve güvenirliliği olan mekik ve sırt kuvvet testi ile karşılaştırılmıştır. 10 testin bitiminden 1 hafta sonra 8 test aynı sıra ile tüm katılımcılara uygulanarak son testler tamamlanmıştır. Çalışmanın sonunda kor bölgesi kuvvet antrenmanlarında kullanılan plank, crunch, çakı, çapraz kol ve bacak, topuğa değme, çift bacak yukarı kaldırma hareketlerinin izometrik kuvvet testi olarak kullanılması

\section{Development and Validity of Izometric Test Battery for the Evaluation of Core Muscle Force}

\begin{abstract}
The aim of the study was to provide the development and validation of an isometric test battery for the evaluation of the strength of the core muscles. Average age of the study was $24,25 \pm 1,91$ years and 30 individuals participated voluntarily. In the study all the participants were warmed up for 10 minutes before all participating force tests. A total of 8 motion tests were performed for the core muscles and the validity and reliability of the 2 central force measures were compared with the force test. After 1 week from the end of 10 tests, 8 tests were applied to all participants in the same order and the final tests were completed. It is recommended that isometric strength tests of plank, crunch, v ups, abbikef, heel touch, legraise movements used in core strength training at the end of the study.
\end{abstract}

Original Article

Article Info

Received: 01.06.2017

Accepted: 16.06.2017

Online Published: 16.06.2017

\footnotetext{
* Sorumlu yazar: Asuman ŞAHAN

E-mail: asusahan@akdeniz.edu.tr
} 


\section{GíRIŞ̧}

Merkez bölgesi (kor), insan bedeninin ağırlık merkezinin de içinde bulunduğu bel-pelviskalça-karın kısımlarını kapsayan 29 farklı kastan oluşan alanı isimlendirmek için kullanılmıştır (Samson, 2005). Anatomik açıdan kor, gövde bölgesinin iskelet sistemi (göğüs kafesi, omurga, pelvis, omuz kemeri) yumuşak dokular (kıkırdak ve bağ dokular) ile bağlantılı vücudun stabilitesini sağlayan ya da aktif hareketlerde rol alan kaslar bütünüdür ve genelidir. Ayrıca merkez bölgesinin tam olarak hangi kaslardan oluştuğu hakkında ortak bir mutabakat olmamakla birlikte farklı sınıflandırmalar mevcuttur. Konuyla ilgili literatür incelendiğinde kor egzersiz ve antrenman uygulamalarının sağlık ve sportif performans olmak üzere iki temel yaklaşım ile ele alındığı görülmektedir ve tercihe göre değişim göstermektedir (Behm ve ark., 2010).

Merkez bölgesi ve kor kasları hakkında farklılıklar oluşmasının temel nedeni bu noktadan kaynaklanmaktadır. Sağlıkla ilişkili kor egzersiz yaklaşımında temel hedef omurga stabilizasyonunu sağlamak ve çeşitli nedenler ile oluşan ve kronikleşen bel ağrılarının rahatlamasını ve problemlerin ortadan kalkması rehabilitasyonudur. Bu amaçla yapılan kor egzersizlerinin genel egzersizlerden daha yararlı olduğu bildirilmiştir (Wang ve ark., 2012). Sportif performans araştırmalarında ise merkez bölgesi; odak noktasına karın, bel ve kalçalar alınmakla birlikte, sternum (göğüs kafesi kemiği) ile dizler arasında kalan bölge olarak kabul edilmektedir (Axel, 2013; Santana, 2005; Hibbs ve ark., 2008).

Merkez bölge kas kuvveti spor performansını olumlu yönde etkileyen bir özelliktir. Kor alıştırmaları hem küçük hem de büyük kas gruplarını aynı anda aktive etmekle birlikte, her biri farklı kaslarını daha fazla çalıştırabildiğinden kor antrenman programında alıştırma konusunda dikkatli davranmak gerekir. Ayrıca merkez bölgedeki bu farklı kasların kuvvetinin belirlenmesi ve kuvvet antrenmanına verilen cevapların takibi önemlidir. Literatürde merkez bölge kaslarının kuvvetini ölçen test sayısı yetersiz olduğu belirlenmiştir. Bu nedenle çalışmanın amacı kor kaslarının kuvvetini ölçmek için yeni izometrik test bataryasının geliştirilmesi ve geçerliliğinin sağlanması olarak belirlenmiştir.

\section{GEREÇ ve YÖNTEM}

\section{Araştırma Modeli}

Çalışmada, Plank, Çift Bacak Yukarı Kaldırma (ÇBYK), topuklara değme, Çapraz Kol Çapraz Bacak (ÇKÇB), crunch ve makas kor testlerinin geçerliliğinin belirlenebilmesi için mekik ve sırt dinamometresi (referans ölçümler) ile yapılan ölçüm sonuçları karşılaştırılmıştır. Güvenilirliğin belirlenebilmesi için ise testler aynı ortam ve koşullarda 1 hafta ara ile iki kez uygulanmıştır (Ercan, 2004; Roberts, 2006).

Çalışma, gövde fleksör ve ekstansörlerinin kuvvetini ölçmek amacı ile planlanmıştır. Bunun için ölçüm sonuçları, referans ölçüm araçları olarak bilinen mekik ve sırt kuvveti ölçüm yöntemleri ile elde edilen sonuçlar ile karşılaştırılmıştır. Ayrıca, test aynı ortam ve koşullarda uygulandığında benzer sonuçlar elde edilip edilmeyeceği sınanmıştır. 


\section{Çalışma Grubu}

Çalışmaya yaş ortalaması $24,25 \pm 1,91$ yıl, boy uzunluğu $179,37 \pm 6,23 \mathrm{~cm}$ ve vücut ağırlığ $75,77 \pm 5,82 \mathrm{~kg}$ olan 30 sedanter erkek birey gönüllü olarak katılmıştır. Katılımcılara çalışma ve uygulanacak egzersiz testleri hakkında detaylı bilgi verilmiştir.

\section{Veri Toplama Yöntemi}

Tüm deneklerden bir gün içerisinde sadece iki maksimal alınmıştır. Diğer testler için kırk sekiz saat dinlenmeden sonra iki egzersizin maksimali alınmıştır. Tüm testler bittikten sonra 1 hafta dinlenme süresi verilmiştir daha sonra tekrar maksimaller alınmıştır. Tüm katılımcılara aşağıdaki alıştırmalar test olarak uygulanmıştır.

Plank Hareketi: Tüm karın kasını çalıştırır. Bunun dışında boyun, sırt, bel, gögüs ve ön/arka bacak kaslarını güçlendirir; duruş bozukluklarını düzeltir. Omzun geride, göğüslerin yukarıda olmasını sağlar. Dirsekler üzerinde parmak ucu yardımıyla tüm vücut sıkılır ve kafa karşıya bakar.

Çift Bacak Yukarı Kaldırma (ÇBYK): Tüm karın kasını, boyun, sırt, bacak kaslarını güçlendirir. Sırt üstü pozisyonunda kollar yanda bacaklar gergin çift bacağı aynı anda yukarı kaldırılır daha sonra yere değdirmeden devam ettirilir.

Çakı: Sırt yerde kollar başın arkasında gergin bacaklar gergin parmak uçları karşıyı gösteriyor daha sonra bacaklar ile kollar ortada buluşur. Karın kaslarını, bacak kaslarını, sırt kaslarını kuvvetlendirir.

Topuklara Değme: Sirt yerde kollar yanda bacaklar omuz genişliği kadar açık boyun yerden kalkar karına bakılır tüm vücut sıkılır ve topuklara değmeye çalışılır.

Çapraz Kol Çapraz Bacak (ÇKÇB): Karın kaslarını, boyun, sırt ve bacak kaslarını güçlendirir. Sırt üstü yatılır bir bacak bükülü diğer bacak gergin çaprazdaki kolumuzu çapraz bacağımıza değdirmeye çalışırız gergin bacak yere değmez.

Crunch: Sırt üstü yatılır eller başın arkasında boyun yere değmeden dizler 90 derece olur ve tüm vücut sıkılır. Sırt, boyun, karın kasları çalışır.

Makas Hareketi: Sırt üstü yatılır eller kalçanın altındadır destek almak amacıyla kullanılır. Bacaklar aşağı yukarı yere değdirilmeden harekete devam edilir. Bacak, sırt ve karın kaslarının kuvvetlenmesini sağlar.

Mekik: Kalça yerde bacaklar bükülü kollar gögüste çapraz tüm vücut sıkı bir şekilde harekete devam edilir.

Sirt Dinamometresi Kuvvet Testi: Sirt ve Bacak Dinamometresi; bir adet ayak zinciri, rahat el tutamaklarıyla kaplı sert alüminyumdan imal edilmiş kaldırma çubuğu ve bir adet kaldırma platformundan oluşur. Kaldırma platformu $61 \times 61 \mathrm{~cm}$ boyutlarıyla her çalışma alanına kolaylıkla taşınabilir. Sırt ve Bacak Dinamometresi, ömür boyu yüksek hassasiyette ölçüm garantisi için yüksek dayanıklılıkta ve sertlikte yaylar içerir. Dinamometre 2,25 kg'lık artışlarla $22-272 \mathrm{~kg}$ arası ölçüm aralığına sahiptir. 


\section{Verilerin Analizi}

Elde edilen verilerin istatistiksel analizinde SPSS 18 istatistik paket programı kullanılmıştır. Tüm grupların tanımlayıcı istatistik analizleri ve dağılımlarına bakılmıştır. Grup içi normallik dağılım özelliğine, (denek sayısının 50'nin altında olması sebebiyle) Shapiro-Wilk testi kullanılarak bakılmıştır. Değişkenler arasındaki ilişkinin belirlenmesi için Spearman korelasyon testi uygulanmıştır.

\section{Bulgular}

Tablo 1: Katılımcıların testlerden aldıkları sonuçlar

\begin{tabular}{lcccc}
\hline \multicolumn{1}{c}{ Testler (n=30) } & $\mathbf{1 . ~ o ̈ l c ̧ u ̈ m ~}$ & & & 2. ölçüm \\
& $\mathbf{A . O} \pm \mathbf{S . S}$ & $\mathbf{r}$ & $\mathbf{p =}$ & AO \pm S.S \\
\hline Plank (sn) & $64,13 \pm 41,08$ & 0.93 & $0,00^{* *}$ & $69,78 \pm 43,44$ \\
\hline Crunch(tekrar sayısı) & $30,20 \pm 11,37$ & 0.64 & $0,00^{* *}$ & $35,00 \pm 19,67$ \\
\hline Çakı(tekrar sayısı) & $21,90 \pm 10,18$ & 0.92 & $0,00^{* *}$ & $24,60 \pm 9,44$ \\
\hline Makas(tekrar sayısı) & $43,71 \pm 15,90$ & 0.83 & $0,00^{* *}$ & $46,04 \pm 19,52$ \\
\hline Çapraz kol ve bacak(tekrar sayısı) & $22,57 \pm 9,04$ & 0.88 & $0,00^{* *}$ & $24,27 \pm 9,69$ \\
\hline Çift Bacak Yukarı Kaldırma(tekrar sayısı) & $18,87 \pm 8,42$ & 0.84 & $0,00^{* *}$ & $20,50 \pm 7,88$ \\
\hline Topuğa Değme(tekrar sayısı) & $26,17 \pm 8,66$ & 0.83 & $0,00^{* *}$ & $27,27 \pm 10,21$ \\
\hline p<0,01** & & &
\end{tabular}

Çalışmada yer alan katılımcıların 1. ve 2. ölçümden aldıkları puanlar arasında tüm testlerde anlamlı ilişki bulunmuştur $(\mathrm{p}<0,01)$.

Tablo 2: Güvenirliliği olan testlerin sırt dinamometresi ve mekik testi ile olan ilişkisi

\begin{tabular}{lcccccccc}
\hline & Plank1 & Plank2 & Crunch1 & Crunch2 & Makas1 & Makas2 & $\begin{array}{l}\text { Topuğa } \\
\text { Değme1 }\end{array}$ & $\begin{array}{l}\text { Topuğa } \\
\text { Değme2 }\end{array}$ \\
\hline $\begin{array}{l}\text { Sirt Kuvveti } \\
\text { (kg) }\end{array}$ & $0,61 * *$ & $0,70^{* *}$ & 0,17 & $0,39 *$ & $-0,05$ & $-0,08$ & 0,30 & 0,28 \\
\hline $\begin{array}{l}\text { Mekik } \\
\text { (tekrar sayıs1) }\end{array}$ & $0,74 * *$ & $0,77^{* *}$ & 0,35 & $0,68^{* *}$ & 0,14 & 0,18 & $0,41^{*}$ & $0,46^{*}$ \\
\hline
\end{tabular}

Güvenirliliği olan testlerle daha önceden normları yapılmış testler arasında yapılan korelasyon analiz sonuçlarına göre plank hareketinin hem sırt kuvveti hem de mekik testi ile en yüksek ilişkiye sahip olduğu belirlenmiştir. Kranç, topuğa değme hareketleri mekik testi ile ilişkili bulunurken, makas hereketi ile sırt kuvveti ve mekik testi arasında anlamlı ilişki bulunmamıştır. 
Tablo 3: Güvenirliliğgi olan testlerin sırt dinamometresi ve mekik testi ile olan ilişkisi.

\begin{tabular}{lllllll}
\hline & Çak11 & Çak12 & ÇKB1 & ÇKB2 & ÇBYK1 & ÇBYK2 \\
\hline $\begin{array}{l}\text { Sirt Kuvveti } \\
\text { (kg) }\end{array}$ & 0,31 & $0,43^{*}$ & $0,57^{* *}$ & $0,70^{* *}$ & $0,56^{* *}$ & $0,65^{* *}$ \\
\hline $\begin{array}{l}\text { Mekik } \\
\text { (tekrar sayıs1) }\end{array}$ & 0,32 & $0,48^{* *}$ & $0,61^{* *}$ & $0,71^{* *}$ & $0,53^{* *}$ & $0,61^{* *}$ \\
\hline
\end{tabular}

Güvenirliliği olan testlerle daha önceden normları yapılmış testler arasında yapılan korelasyon analiz sonuçlarına gore çakı, çapraz kol ve bacak ve çift bacak yukarı kaldırma test sonuçlarının sirt kuvveti ve mekik testi ile ilişkili olduğu olduğu belirlenmiştir.

\section{TARTIŞMA VE SONUÇ}

Çalışmanın amacı, kor kaslarının kuvvetini ölçmek için izometrik bir test bataryasının geliştirilmesi ve geçerliliğinin sağlanmasıdır. Çalışmada uygulanan testlerin 1. ve 2. ölçüm sonuçları arasında yapılan korelasyon testi sonuçları uygulanan testlerin güvenirliliği hakkında bilgilerin edinilmesi için test sonuçlarının geçerliliği ve güvenirliği olan mekik ve sırt kuvveti testi ile ilişki sonuçları ise testlerin geçerliliği olarak yorumlanmıştır. Literatürde benzer bir çalışmaya rastlanmamıştır.

Optimal sportif performans için merkez bölge antrenmanları gereklidir ve göz ardı edilemez. Merkez bölge kuvvet ve stabilitesinin rolünü belirlemek ve spora özgü olarak etkinliğinin belirlenmesine ihtiyaç duyulmaktadır. Tek bir test bireyin kor stabilite/kuvvet değerlerini belirleyebilir fakat sportif performans açısından tüm vücut hareketlerine ilişkin kor antrenmanın rolünün doğru anlaşılması spora özgü testler yapmayı gerektirir (Nesser ve ark., 2008).

Yapılan istatistik analiz sonucunda çalışmada plank, crunc, çakı, makas, çapraz kol çapraz bacak, çift bacak yukarı kaldırma ve topuğa değeme testleri güvenirliliği olan testler olarak belirlenmiştir $(p<0,00)$. Bu testlerin mekik ve sırt kuvveti testi ile olan ilişkilerine bakıldığında ise makas hareketi dışında tüm hareketlerde anlamlı ilişkiler belirlenmiştir. Özellikle plank hareketinin kor bölgesinin kuvvetini belirlemek için güvenilir ve geçerliliği en yüksek test olarak kullanılması önerilmektedir. Çalışma sonuçlarına gore; genel olarak testlerin gövde ekstansör ve fleksörlerinin kuvvetinin belirlenmesinde geçerli ve güvenilir bir araç olabileceği söylenebilir.

\section{KAYNAKLAR}

Axel, T.A. (2013). The effects of a core strength training program on field testing performance outcomes in junior elite surf athletes. California State University, Long Beach, 89; 1523042

Behm, D.G., Drinkwater E.J., Willardson, J.M., Cowley, P.M., (2010). The use of instability to train the core musculature. Appl. Physiol. Nutr. Metab. 35, 91-108.

Ercan, İ., ve Kan, İ. (2004). Ölçeklerde geçerlik ve güvenirlik, Uludağ Tip Fakültesi Dergisi, 30 (3), 211-6. 
Hibbs, A.E., Thompson, K.G., French, D., Wrigley, A., \& Spear, L. (2008). Optimizing Performance by Improving Core Stability and Core Strength. Sports Med, 38(12), 995-1008.

Nesser, T.W., Huxel, K.C., Tincher, J.L., Okada, T. (2008). The relationship between core stability and performance in Division I football players. J, Strength Cond Res., 22,1750 1754.

Roberts, P., Priest, H., Traynor, M. (2006). Reliability and validity in research. Nursing Standart, 20 (44), 41-5.

Samson, M.K. (2005). The Effects of a Five-Week Core Stabilization-Training Program on Dynamic Balance in Tennis Athletes, Master's Thesis, West Virginia University.

Santana, J.C. (2005). Strength training for swimmers: Training the core. Clin J Sport Med, 2(27),40-42.

Wang, X. Q., Zheng, J. J., Yu, Z. W., Bi, X., Lou, S. J., Liu, J., et al. (2012). A meta-analysis of core stability exercise versus general exercise for chronic low back pain. PloS one, 7(12), e52082. 